\title{
Between, Within and Across Cultures ${ }^{1}$
}

\author{
ROBERT GLUCK \\ Department of Music, University at Albany, 1400 Washington Avenue, Albany, New York 12208 USA \\ E-mail: gluckr@albany.edu
}

\begin{abstract}
The phenomenon of contemporary composers reaching across cultures in search of inspiration, musical materials and forms, and new ideas is not a new one, but it is occurring now with greater frequency. Some seek to join inherited traditions from within their own ancestral cultures with new traditions from the West or with new technologies. Some are Westerners exploring traditional musical forms and aesthetics from cultures different from their own. The process of engaging interculturally raises complex issues, at times challenging historical attitudes towards the culture of 'the other'. The author considers a wide range of motivations for this emerging body of work, surveying the range of approaches that composers have taken, and urges the cultivation of cultural sensitivity. This essay proposes what the author terms a 'reflective compositional process' with which composers can explore their motivations and compositional strategies and consider the relationships inhering between materials and cultural origins. Implications for works engaging new technologies are considered throughout the essay.
\end{abstract}

\section{INTRODUCTION}

Issues of culture have recently become an increasing focus of interest in electroacoustic music (De Souza 2005; Fischman 1999; Gluck 2005c, 2006a, 2006b; Keyes 2005; Whalley 2005). This reflects a departure from earlier assumptions that the aesthetics of this field transcended cultural boundaries, despite the European and North American aesthetics characteristic of its founding era of the 1950s and 1960s. The notion that sounds within electroacoustic music might be listened to for their cultural content, rather than as objects, represented a shift from the original thinking of the studios in Paris and Cologne. One finds the seeds of a new perspective as early as Luc Ferrari's Presque Rien (1970) and Karlheinz Stockhausen's Telemusik (1966) and Hymnen (1966-67). Telemusik, in particular, represented the beginning of a new trend, which has only recently begun to expand, of composers incorporating into their work aspects of cultures other than their own. This development comes as no surprise since

${ }^{1}$ Many thanks to Warren Burt, Aileen Gluck, Pamela Lerman, Alireza Mashayekhi, Philip Royster, Richard Teitelbaum and Barry Truax for their critical comments and responses to the various drafts of this essay. composers are increasingly becoming more aware of other cultures due to mass media, expansion of the Internet, global trade, the availability of recordings of music from many cultures, legacies of colonialism, perceptions of ecological crisis, and the ubiquity of sampling technology.

A global perspective in which national boundaries become less important can potentially expand the pool of resources available to spark the musical imagination. Such a perspective is prefigured in the work of early Modern European composers. For some, new ideas, aesthetics, forms and materials from the East helped provide new strategies to organise and structure musical materials, as tonality became exhausted in the late nineteenth century. Claude Debussy drew upon ideas from Japan and Javanese gamelan in search of new conceptions of time, space, timbre, directionality or its lack, gestural shape and pitch organisation. Debussy discovered in the woodcuts of Katsushika Hokusai (1760-1849) a sensibility that influenced his use of sounds to convey sense impressions and symbols, analogies to reflections of light and shading, and shifting patterns (Metropolitan Museum of Art website, accessed 2007).

The search for new ideas within other cultures continued among twentieth-century composers, among them Lou Harrison, Henry Cowell, Béla Bartók, John Cage, Olivier Messiaen, LeMonte Young, Colin McPhee, Terry Riley and Steve Reich. Cowell studied the music of several Asian cultures as he developed his highly personal approach, one that collapsed national and stylistic boundaries, declaring: 'I want to live in the whole world of music!' (Weisgall 1959: 498). Bartók explored folk traditions within his own Central European culture and, like Cowell, he used them largely for musical inspiration rather than as quoted material. Many of the folk elements within his works are actually of Bartók's own invention (Hungarian Academy of Sciences Institute for Musicology 2005). John Cage found in East Asian culture processes that could be used in the composition and performance of his music (Cage 1961; Corbett 2000). Another example of intracultural influence is the movement by white musicians in the United States and Great Britain to draw upon the music 
of African-American blues, jazz, soul, and rhythm and blues to create their own versions of these forms, the most famous being rock and roll. Cage specifically rejected improvisational means found in these traditions (Corbett 2000; Lewis 1996).

Although many composers have been influenced by or borrowed from other cultures, cultural artefacts do not exist in a vacuum and art forms are not separable from the wholeness of a group's culture (Bruyn 1966; Hall 1959, 1966, 1976; Sprague 1980). The expressive arts are a core means by which members of a society articulate their sense of self, their history, struggles and strivings. Artistic traditions develop within contexts that are weighted with rich webs of historical and political meanings. Drawing upon other traditions raises issues about freedom of expression, cultural boundaries, ownership and understanding, ethics and propriety, and cultural, ethnic and national identity. What a composer may view as a natural aspect of the creative process may be interpreted, by others, as an act of cultural appropriation.

This is especially the case when intercultural relationships take place within a context of unequal power relations. The availability of Japanese prints in France was a consequence of the economic power of Europe, which had long sought to open Japanese markets for trade. By means of forced trade, consumer goods and designs viewed as exotic and fashionable became available throughout Europe, among them 'Oriental' fabric motifs and carpets, along with pentatonic melodies, which became available for absorption into the fabric of western musical compositions (Wade 2005). Likewise, the emergence of rock and roll took place within the context of asymmetrical power relations between races in American society, the influence of the marketplace in popular music, and issues of cultural authenticity (among others: Baraka 1963, 1991; Davis 1995; Friedlander and Miller 2006; Mahon 2004; Phinney 2005; Rabinowitz 1991; Rogin 1998; Wilson 1983). Some parallel issues may be found in societies, such as Australia, that include aboriginal cultures (Burt 2007). It is in light of these concerns that some cultural theorists have suggested that crosscultural borrowing can take the form of cultural appropriation (Coombe 1997; hooks 1990; Said 1978).

Another question relevant to a consideration of crosscultural borrowing is whether a particular musical tradition can travel across cultures with its musical integrity intact. Composer Toru Takemitsu observes that western music is more 'transportable' than Japanese music because the former can generally be abstracted into relations between fixed pitches, tying the essence of a work to notes rather than to specific instrumentation. In contrast, the nature of the Japanese biwa, a stringed instrument whose construction introduces a noise element, renders its music unrealisable with other instruments and thus not transportable
(Takemitsu 1995: 59-67). Similarly, Christopher Dobrian comments that a distinguishing feature of the Korean stringed instrument, the daegeum, is 'constant fluctuation in the course of a note' (Dobrian 2007). He discovered inherent difficulties when attempting pitch tracking with a computer because pitch stability, a feature of western European instruments, is not a quality of the daegeum or, more generally, of Korean musical aesthetics (Dobrian 2004). The lack of pitch stability renders daegeum music non-transportable to western instruments. This raises the question of whether it is possible for a composer to borrow from another culture's tradition when its music is not easily transportable.

The advent of sound recording and, subsequently, Pierre Schaeffer's conception of the object sonore (sound object) (Schaeffer 1966) would appear to render all sounds transportable since musical sounds became artefacts, subject to being infinitely copied. The experience of listening becomes abstracted not only from the sound source, a phenomenon termed 'schizophonia' by R. Murray Schafer (Schafer 1977), and original acoustical environment, but also from cultural context. It would stand to reason, therefore, that a recorded sound from another culture is a sound object like any other, available for use in whatever way a composer wishes.

In fact, recorded sounds can capture a living, breathing aspect of cultural or natural life and composers have the choice to give them new life when replayed or treat them as objects for use, with the potential for misuse. A fear expressed by Walter Benjamin that technology allowing infinite copying might lead to a loss of the "traditional values of cultural heritage' (Benjamin 1969) is reasonable but not inevitable. To offer one counter argument, the availability of recordings of traditions that have gone out of vogue have at times led to the rediscovery of those traditions within the culture of origin. As access to digital compositional and recording tools broaden, culturally sensitive compositional practice means placing self-limitations on one's freedom to treat material however one wishes. Is it not already the case that every composer self-censors her or his own work during the editing process? Are not all compositional practices already to some degree self-reflective?

To further complicate these issues for composers, electroacoustic music is a field that has historically viewed itself as culturally neutral, although its artistic values were grounded in European cultural history. We sometimes fail to recognise that while the world may appear to be smaller, most of us remain creatures of local concerns, loyalties, motivations and tastes. We love the things we know from childhood, we are loyal to the people we view as most like us, and we view the particular lens through which we see the world as normative. When we consider our own aesthetic 
assumptions to be neutral or reflecting a universal, we become less able to objectively analyse these issues. It is with the supposition that the obstacles lie largely in our habituated perceptions and attitudes that I propose a self-reflective process for composers who seek to engage crossculturally.

\section{REFLECTIVE COMPOSITIONAL PROCESS: MOTIVATIONS AND SELF-QUESTIONING}

In previous articles (Gluck 2005a, 2005b, 2007a), I considered particular instances in my own work where I adapted non-western musical instruments, within the context of questions about crosscultural borrowing. In an essay published in Organised Sound (Gluck 2005a), I pointed out that art making has always relied on borrowing and crosscultural exchange, from folk traditions to Bach's reuse of his (and others') own work, to Ives' use of American hymns and patriotic tunes to the eighteenth- and nineteenth-century European use of Turkish melodies, to the evolution of the banjo, none of which prevented the original authors from representing their own culture. I concluded that borrowing is unavoidable and that crosscultural borrowing can be respectful and legitimate, if not invaluable. I noted, however, that three elements must be present to achieve respectful adaptation: an appreciation of the contents and value of the other culture on its own terms; a desire to speak from one's own personal artistic voice without mimicking the other culture, and an awareness that can be articulated to an audience of the fine line between creative borrowing and disrespectful appropriation.

I reached this conclusion with substantial unease and turmoil. My initial conclusions were less optimistic, and were challenged by a number of colleagues. They had a point, but not one that settled the issue for me, prompting further examination. I discovered an opportunity to test my observations while writing about music by Iranian composer Alireza Mashayekhi. To offer a single example, when I came upon shifting sound masses in Mashayekhi's Concerto for Violin and Orchestra, op. 96 (1988) (Sound example 1), I reflexively referenced Gyorgi Ligeti and Krysztof Penderecki. Upon further reflection, I realised that this was but one of several ways to contextualise these features. Visual images came to mind, of light refracted through a slowly shifting prism, revealing changing details of sonic colour, density, shape and gesture. These could be referenced as Sufi mystical conceptions of unity and multiplicity. This experience suggested to me how unconscious are the culturally grounded assumptions that I make in my musical life. It was also a reminder that Henry Cowell was correct when he observed: 'all music is ethnic music' (Adams 2001), irrespective of our cultural background, aesthetic perspective, or musical milieu, including western standard practice.
The implications of the criteria that I suggested in my 2005 article - appreciation for original context, nonimitation and respect - are that compositional practice should be reflective. The term 'reflective practice' has two roots: the first, from the field of educational pedagogy, refers to learning as a continual process in which the practitioner carefully contemplates the implications of what one learns during and after concrete personal experience (Schon 1983). The second is grounded in the practice of Vipassana, a form of Buddhist meditation often translated as 'Mindfulness', in which the practitioner observes her or his thoughts without judgement. There are many fields, from psychology to organisational development to nursing, that synthesise ideas and practices deriving from both uses of the term. Related ideas have been developed in other fields: sociologists and anthropologists (Bruyn 1966; Hall 1976; Spradley 1980) have long considered how an observer can learn to understand another culture on its own terms; educators have developed the term 'reflexivity' to refer to a process of self-questioning to increase self-awareness (Nagata 2004). Spradley (1980) speaks of the importance of introspection for the participant observer in anthropology.

For purposes of this essay, reflective compositional process is defined as an approach by which the composer engages in a repeated process of selfreflection, carefully considering motivations, context and implications of compositional decisions, complementary to considerations of formal and aesthetic artistic criteria. Like a social scientist, the perspective of the composer is one of empathy for the culture under consideration:

by taking the role of his subjects he re-creates in his own imagination and experience the thoughts and feelings which are in the minds of those he studies. It is through a process of symbolic interpretation of the 'experienced culture' that the observer works with his data and discovers meanings in them. (Bruyn 1966: 12)

Ethnomusicologist Mantle Hood offers a useful model that can inform a self-reflective process, a concept that he calls 'bi-musicality'. This is the ability to function competently and with understanding within the musical practice of another culture. Hood notes that every culture's music can be appreciated only on its own terms and he offers the example that basic western musicianship, such as having perfect pitch, actually represents a 'conditioned prejudice to overcome' interfering with the musician's ability to hear 'microtonal inflections' (Hood 1960: 56). The needed skill set can be gained through learned sensitivity and actual musical performance experience. 'If his desire is to comprehend a particular Oriental musical expression so that his observations and analysis as a musicologist do not prove to be embarrassing, he will have to persist in practical studies until his basic musicianship is secure' 
(Hood 1960: 58). 'Bi-musicality' requires developing an awareness of the assumptions and conditioned responses that colour our musical experience and thus our ability to engage with the music of an unfamiliar culture.

Composers approach their work in many different ways, from how they draw upon experience and inspiration, tap the unconscious (Harvey 1999) and approach choice of materials, form and compositional process. It is thus difficult to outline a single model for a reflective compositional process. There are composers who begin their work by selecting materials, others who begin with ideas about structure, followed by the selection of forms, and others yet whose models are hybrids. And of course there are approaches utterly distinct from these more conventional approaches. A reflective composition process relating to cultural issues, however, potentially includes five stages. The first is a consideration of the composer's motivations for her or his choice of materials and forms. This stage may be repeated before and after choices are made, and yet again further into the compositional effort. The second is a consideration of one's relationship with the culture in question. The focus of stage three is selecting a strategy for crosscultural engagement. Fourth is a reconsideration of all aspects of the work from two perspectives: that of a member of the culture in question and that of an observer external to that culture. The fifth and final stage is a consideration of the overall effort in light of initial motivations, strategies and other factors, in light of any revisions made during prior stages in this engagement.

\subsection{Motivations}

Let us first consider the issue of motivations, of which many possibilities can be identified. A few examples follow.

\subsubsection{Curiosity}

Gaining access to recordings and performances of unfamiliar forms of music can suggest new ideas for one's own work. One can begin with more distanced musicological study, empathetic personal encounter or more casual exploration.

\subsubsection{Search for new ideas and options to address compositional issues, roadblocks and constraints within one's own work or cultural milieu}

Claude Debussy, discussed above, is an example of a composer who sought crosscultural models to address difficulties encountered by European composers at the threshold of Modernity. Debussy's practice was to seek inspiration from, rather than literal quotation of, materials from other cultures.

\subsubsection{Coming home: the discovery or affirmation of one's own family's cultural heritage}

A child of immigrants who has become largely or fully acculturated into the dominant culture awakens to a new awareness of her or his ancestral culture. Sometimes this discovery may be its first occurrence in generations. In some cases, this composer considers the implications of the recovered legacy for his or her own hyphenated identity or work. Another possibility is the composer born in one country, but adopted by parents who come from a different culture. Later in life, the composer explores the biological parents' culture and may view him- or herself as a member of a community in cultural disapora.

\subsubsection{Global consciousness}

This interest may be motivated by a desire to discover and express underlying commonalities between peoples. One expression of this is soundscape composition that encompasses a multiplicity of cultures or seeks to transcend their boundaries. Another motivation is the experience of people becoming long-term residents or citizens in countries culturally different from that of their birth, a phenomenon that can be experienced in many different ways, with ease, confusion, dislocation, loss, relief ...

\subsubsection{Vogue}

This includes use of cultural materials for decorative purposes: for example, to represent the exotic. Motivations can include naivety, ignorance, popularity or commercial gain and the results can be viewed as benign or as cultural imperialism.

\subsubsection{Boundary testing}

Here the composer seeks to challenge the norms and limits of his or her own culture. This can include trying on the symbols and materials of others. This can be due to boredom with one's own culture or a desire to engage in behaviour viewed as transgressive.

There are times when one's motivation is relatively transparent. Sometimes it can be elusive, especially when one's stated goals do not coincide with what is discovered through a process of self-reflection or review by others. Critical feedback can provide a useful check on one's own assumptions, solicited from members of a culture, including peers within one's own musical community and others outside of it. Few of us are as self-aware of our motivations as we think we are. I list these motivations largely without making value judgements, believing that honesty can lead to critical assessment on the part of composers themselves regarding appropriateness of choices. 


\subsection{Self-questioning}

Stage two is no doubt the thorniest of the five because it involves issues that are rarely considered in discussions about music. It is not my intent to suggest strict rules nor is it to suggest policing creative decision-making. Nor does any specific answer to these questions imply any particular course of action. Rather, my goal is to encourage self-questioning which might lead towards greater clarity and thus informed choices. Here are several sample questions about materials and forms to ponder:

- Have I accurately and with specificity identified and researched the cultural origin?

- To what degree am I familiar with relevant meanings and import within the culture of origin?

- What is the relationship between my own culture and the other? What is the history of those relations? Do they involve issues of unequal power relations, economic, political or other, and, if so, what might be implications for present practice?

- What is my personal relationship with the culture in question?

- Are the materials in question well represented in recordings by traditional practitioners? Are they in danger of becoming lost or considered obsolete?

- Is there an existing non-traditional musical practice within that culture that engages these materials?

- Does the material remain recognisably identifiable? Does its original integrity remain intact?

- What is the relationship between my use of the material and traditional practice? Are there issues of cultural sensitivity on the part of traditional practitioners about the non-traditional use of these materials? Are there relevant issues of provenance - that is, to what degree is the material considered by its own practitioners to be protected from outside use?

- What has been the reaction of members of the culture in question to my new work? Can I imagine performing the new work to members of that culture or within that country?

- How do I define my motivations within the options listed in stage 1? What is my comfort level with acting on that motivation?

- Do any of these questions trouble my conscience? If I had to begin again, would I make the same decisions?

\section{STRATEGIES OF CULTURAL ENGAGEMENT}

The third stage is reflection with respect to models for engagement. I now consider several possibilities that have been utilised by composers. Some of these flow out of or suggest motivations outlined above.
3.1. Incorporating traditional elements from one's own culture into a new work that is aesthetically and formally removed from the original source.

This can include electronic treatment of traditional instruments or voice, such as pipa in Chinese composer Dajuin Yao's cinnabar red drizzle (1999) (Yao 1999), tar in Persian-American composer Dariush Dolat-shahi's Sama (1985) (Dolat-shahi 1985), the ram's horn in Jewish-American composer Alvin Curran's Shofar (1990, with subsequent versions in 1994 and 2006) and in my own Sshofar (2002), Shofar (2002) and Shofaralong (2001) (Gluck 2003), daegeum in Korean composer Sung Ho Hwang's Contrast (1993) (Hwang 1999), and sitar and robotic Indian drummer in IndianAmerican Ajay Kapur's Digital Sankirna (2007) (Kapur 2007a) and other works. Kapur explores humancomputer interaction, drawing upon classical Indian rules of improvisation (Kapur 2007b).

In most of these examples, instrumental techniques tend to retain a close relationship with traditional performance practices. A related approach incorporates traditional musical elements, such as mambo dance rhythms in Peruvian-Israeli-British composer Rajmil Fischman's Alma Latina (1997) (Fischman 2001) and structural ideas from the Persian radif in IranianAmerican composer Shahrokh Yadegari's Tear (1999) and Migration (2005) (Gluck 2005c, 2006a, 2006b, 2006c; Yadegari 2004). What is so successful about Fischman's and Yadegari's work is how integrally and unselfconsciously each composer integrates culturally specific ideas into the overarching fabric of their music. Fischman often shapes the rate of motion of the musical materials to suggest a perception of dance rhythms, and his quotations from Cuban 'Mambo King' Dámaso Perez Prado subtly punctuate complex electronic musical gestures. Yadegari's work displays its cultural influences simply and directly in the manner that the musical patterns unfold in time, as if continually turning a prism through which light streams.

3.2. Use of traditional instrumental or vocal sounds by composers outside the culture from which the materials originate.

Examples abound in popular music, most notably Paul Simon's use of rhythms and performers from South Africa in Graceland (1986) (Simon 1997) and from Brazil in The Rhythm of the Saints (1990) (Simon 2004), and Peter Gabriel's use of Middle Eastern and African musical materials in Passion (1989) (Gabriel 2002). In the works on his recording entitled Al Nur (2001) (Cipriani 2001), electroacoustic music composer Alessandro Cipriani layers, loops and processes traditional vocal and instrumental performances to create 'a rewrite of pieces of oral traditions (more or less complex)' (Cipriani 2001). Sometimes the sources are 
derived from a single culture (the Chinese song 'Reflection of the Moon over Two Springs' combined with his own 'Into the Light') and at other times interrelate multiple cultures - for example 'Trilogy', which incorporates elements of Islamic, Christian and Jewish chant, seeking points of commonality within the sonic and modal characteristics of the three. Cipriani's goal was to be guided by the material itself and to consider where it led him.

There are also works where a composer from one culture reaches into the traditional instrumental resources of another culture to create a work. One example that shows understanding of and empathy for the other culture is Christopher Dobrian's Interproviplaytion VI: Mannam (Encounter) (2003) for daegeum and interactive computer system. In some respects, the work is composed in a distinctly nontraditional aesthetic whereby the computer tracks information about daegeum pitch, loudness and timbre, and 'modifies the sound of the daegeum in real time, stores and reconfigures excerpts of the played music, and provides harmonic accompaniment in 'intelligent' response to the daegeum notes'. But at the same time, the written score for daegeum remains relatively close to inherited traditions, 'composed in idiomatic style'. The performer must be comfortable with both the inherited and new traditions, since the score 'leaves the performer considerable opportunity for rubato, ornamentation, and even occasional reordering of phrases, in order to respond to the computer's performance, which is different every time the piece is played' (Dobrian 2003).

Some composers seek mentors within another culture to offer more of an inside view of a musical tradition other than one's own. Richard Teitelbaum recalls (Teitelbaum 2007):

To prepare to compose 'Blends' (1977) for shakuhachi, synthesiser and percussion, I apprenticed for a year with shakuhachi master Katsuya Yokoyama in Tokyo. Later, when I decided to incorporate Turkish musical traditions within my opera 'Z'vi' (2005), a work very much about meetings between cultures, I chose to create an improvisational part within the score for a master of traditional Turkish music, Omar Faruk Tekbilek, who sings and plays ney, zurna and Turkish percussion instruments.

Curtis Bahn, composer, performer and designer of interfaces for what he terms 'electronically enhanced acoustic instruments', discovered within his personal spiritual practice an affinity for the music of another culture (Bahn 2007):

I have been a serious yogi for several years and this has led me to a study of Hindu and Buddhist chant, philosophy, meditation, and an interest in musics that reflected these practices. In terms of musical instrument design, the acoustic basis of Indian instruments such as the Sitar and the Sarangi reflect the notion of resonance through the use of a set of sympathetic strings tuned to the particular raga being performed. This also reflects the larger cosmological notion of the practitioner being attuned to, and resonating with, the vibrational energies of the universe. Several years ago, I contacted an Indian music teacher saying that I was interested in talking to her about Indian music theory - not really knowing fully what I was getting myself into. She said that the only way to understand the music was to practice and embody the concepts, and that I should come over to begin sitar lessons that day. What followed has now been three years of listening, practice and study, and I am just beginning. I have traveled to India numerous times to exchange ideas and work with traditional musicians and contemporary media artists. Through the Academy of Electronic Arts in Delhi, I have helped to organize several new media conferences, and an upcoming workshop on interactive electronics and 'culturally sensitive' interfaces for Indian music including a DIY workshop.

I am now 'sitting with' the American bansuri (Indian flute) virtuoso Steve Gorn on a weekly basis. The concepts I learn are applied both to my emerging practice of Hindustani classical music, and to the development of my current interactive performance systems. I have worked with Indian instrument makers to modify my sitar and dilruba (a small bowed string instrument) with sensors and electronic pick-ups, and I have written an interactive interface which is sensitive to instrumental gestures such as meend (the bending of the sitar string), and the articulation of numerous ragas. I'm not sure where this practice will take me, but I am finding a very fruitful area of exploration in the relationships between raga as an improvisational form, and contemporary electronic media performance.

Karlheinz Stockhausen's Telemusik (1966) interrelates recorded music from Japan, Bali, China, Hungary, Vietnam and other cultures with electronic sounds. Using a compositional approach the composer calls 'intermodulation' (Stockhausen 1978), Stockhausen offers the work as an exemplar of a future global compositional model, the culmination of an unfolding process that moves from the destruction of distinctive cultural forms through amalgamation, to a period of distinct cultural conservation, to a stage of individualistic free expression in which composers can draw from an intercultural reservoir of possibilities (Stockhausen 1978):

This first phase of the intermingling and integration of all the earth's musical cultures will be followed by the opening of a second where - just like a mounting spiral whose windings constantly bring it to the same point one level higher - a powerful trend opposing the move towards uniformity will establish itself. After a time when conservation predominates, the emphasis in individual spheres of culture will once again be on developing original forms as a contribution to harmony between all cultural groups. There will even be created a kind of artificial new folklore, utilizing electronic equipment and heaven only knows what other technical apparatus. (In this context, for once 'artificial' really means 'artfully made.') Such individual styles, consciously shaped from the most remarkable hybridization of all historical and 
freely-invented possibilities, will then extend the world of musical forms and rites of performance in a completely new way.

Frances White (1990) is highly critical of Stockhausen's approach, questioning whether the actual composition matches his rhetorical description. White holds that Stockhausen almost exclusively selects non-western musical examples, often unidentifiable, which are treated to 'unification through annihilation'. White believes that the result of modulating the culturally grounded recordings with electronic sounds (and vice versa) is less a world music than an expression of a 'subject and object' relationship in which only the composer has a voice. White contrasts the Stockhausen work with Charles Dodge's 'Any resemblance is purely accidental' (1980), which she views as a respectful treatment of a recording (of tenor Enrico Caruso) from within the composer's own culture.

My own perception of Telemusik is that it is best considered within the context of acousmatic music, rendering the identity of its source material largely incidental. The listener who is not familiar with Stockhausen's conceptual programme for this work is likely to detect neither the identity of his sound sources nor the core idea motivating its composition. One utilises acousmatic listening to experience this work, thus depriving the sound sources of any potential culturally defined meaning. The goal of musique concrète is indeed to annihilate one's sources. The problem here, as White observes, is that Stockhausen's sources are treated as objects and not as active agents participating in a collaborative process. In the context of musique concrète, this is not problematic. But Stockhausen presents a contradictory message, asserting that the idealised future composer who functions as an individualistic creator, drawing upon material from other cultures, creates a form of expression that is universal. Stockhausen brings us full circle to the early Modern idealised concept of the western composer as autonomous genius. Lack of sensitivity to sources is implicitly considered to be a tool that results in a music for all peoples.

\subsection{Use of recordings from human and natural environments within one's own culture.}

Alberto Villalpando's Bolivianos! (Bolivia, 1973), Ricardo Teruel's Nuestra Cultura Vegeta (Venezuela, 1976) and Joaquin Orellana's Humanofonia (Guatemala, 1971) use human voices and environmental sounds to articulate sociopolitical messages (Dal Farra 2003, Gluck 2006b). Bolivianos opens with highpitched electronic sounds, possibly suggesting radio transmissions, and dense clusters of sustained sounds. Suddenly, two or more recognisable voices begin to recite the word 'Bolivianos': one lyrical and female, another gravel-like and male, laughing in a sardonic fashion, suggesting the horror of the disastrous Chaco War between Bolivia and Paraguay during the early 1930s that eventually led to a political revolution in Bolivia. Spoken texts are juxtaposed with the electronic sounds, addressing the social and educational problems faced by the country. The effectiveness of this work owes to its juxtaposition of diverse elements which come together to create a unified message.

Soundscape compositions, by definition referencing a specific geographical place, take a very distinct approach to the use of recognisable recorded material. Cultural allusions are more subtle since sounds from nature can offer a certain universality. Cecile le Prado's Le Triangle d'Incertitude (1996) interweaves sounds of sea, boats, sailors and life from the French coastline. Canadian soundscape compositions, such as Barry Truax's Pacific Fanfare (1996) and Hildegard Westerkamp's Beneath the Forest Floor (1992) are set in specific locales in British Columbia and use subtle digital signal processing to suggest a sense of place in the imagination of the listener. Similarly, Thomas Gerwin's Fluss durchs Ohr: Klangbilder vom Neckar (1998) features sounds of people and nature along the Neckar River in Germany, and Annea Lockwood's $A$ Soundmap of the Hudson River (1989) follows the unfolding of the river from its source to the point where it flows into the Atlantic Ocean. While many of these works reference nature more than human culture, they are all specific to the environment of a locale.

\subsection{Soundscape compositions by composers outside the culture from which the materials originate.}

The goal of Hildegard Westerkamp's Into India (2002) is an empathetic exploration of a country in which the composer spent substantial time over a ten-year period working closely with people and recording sound environments. The sounds 'form the language with which I speak, of a relationship, of a love, that I developed for this initially very foreign place' (Westerkamp 2002). Like her previous work set in her Canadian home environment, Westerkamp's compositional techniques feature juxtaposition and attention to spectromorphological detail, including the use of subtle filtering. A related cluster of works are more documentary in approach, among them David Dunn's The Lion In Which The Spirits Of The Royal Ancestors Make Their Home (1995) set in Zimbabwe, East Africa, and Steven Feld's Rainforest Soundwalks (2001), set in the Bosavi rainforest in Papua New Guinea.

\subsection{Creation of a culturally neutral space in which performers from different cultures can meet on equal footing.}

Richard Teitelbaum pioneered this unusual and challenging approach when he organised World Band at 
Wesleyan University in 1970. Western and non-western musicians gathered for combined social and musical occasions, in which:

Open field situations were created which allowed several world musics to co-exist, interact, and inter-penetrate simultaneously in the same space, and on an equal basis. No musical structure was preconceived, but rather allowed to evolve out of the collection actions of all participants .... At rehearsals no verbal instructions were given, no rules enunciated, no written scores employed. The music was shaped through attention to sound. In this way, a variety of forms and textures emerged, as well as unspoken but very real common understandings. One of these was that no one personality was to dominate. (Teitelbaum 1972)

Teitelbaum and, in one case, Nam June Paik, composed several scores for the World Band that exemplifies this approach. These three examples offer a flavour: Play your own music (World Band Piece No. 1), Choose two partners from different areas and play a trio (World Band Piece No. 5), and Compose music for a performer from the nation that is the number 1 enemy of your own. Ask him to compose something for you. Perform the pieces (World Band Piece No. 16, composed by Nam June Paik). Music-making and friendships emerged as a result of the neutrality of the setting and Teitelbaum's emphasis on the integrity of individual cultural expression.

\subsection{Exploring the possibilities for adapting and extending musical traditions within one's own culture.}

Korean-American composer and performer Jin Hi Kim learned to play the komungo in Korea as an adolescent. In college in Korea, Kim began to compose works combining Korean and western instruments, but it was in the United States that she started to improvise in avant-garde and crosscultural settings. Subsequently, Kim began to integrate electronic processing into her performances (Kim 2001a, 2005). In works such as Saturn's Moons (2001) (Kim 2001b), Kim uses electronics to expand upon the qualities of timbre and intonation inherent in the instrument. She does so, as we will discuss below, with deep concerns about how easily the integrity of an inherited tradition can be damaged.

Having trained exclusively in western music, Japanese composer Toru Takemitsu entered new territory when he began to study and eventually incorporate traditional Japanese instruments within his work. His initial interest was not rooted in cultural exploration, but rather in the sonic qualities of the instruments. In November Steps (1967) (Takemitsu 1994), his compositional choice was to not blend Japanese and western instruments. Rather, 'through juxtaposition it is the difference between the two that should be emphasized' (Takemitsu 1995: 87). The work opens with passages of lush strings and dense brass chordal sections which give way to something radically other: duet passages for biwa and shakuhachi. The contrast between the massed violins and the short, percussive sounds of the biwa could not be more stark. The listener is asked to consider whether one can find a common language between traditions or whether, as the composer suggests, the chasm cannot be crossed, except through a juxtaposition of differences.

Iranian composer Alireza Mashayekhi trained equally in western and traditional Persian music, studying electronic music with Gottfried Michael Koenig in Utrecht, The Netherlands. In his piano music, especially $A$ la recherche du temps perdu, op. 111 (1994) (Sound example 2) and the series entitled Short Stories, op. 106 (1993) (Mashayekhi 2004), Mashayekhi reinvents the piano not as a polyphonic instrument but as one capable of playing vertically juxtaposed modal elements. What may sound to westerners like chordal structures are in fact fragmentary horizontal modal elements derived from the Persian dastgah. Rather than harmony, one discovers what might better be termed the 'flavour', 'colour' or 'essence' of the mode. In his earliest electronic works, Shur (1968) (Sound example 3) and East-West (1973) (Mashayekhi 2005), both composed in Utrecht, one finds a predominance of distinctly melodic elements - modal and microtonal - organised within shifting patterns, not unlike traditional Iranian music or Islamic art.

Chahargah II for tar, violin, orchestra and tape, op. 140 (1999) (Mashayekhi 2002) (Sound example 4) is one of several works in which the composer utilises algorithmic techniques to determine fine details within larger structures. One cannot distinguish clearly between foreground and background; music played by a live solo performer is juxtaposed with recorded sounds of Persian instruments. Both elements draw upon Persian modal improvisational forms. The recorded sections appear to be at the core of the work, but both elements are equally dynamic and in the foreground.

\subsection{Composers trained in two musical cultures reconciling elements from each tradition within the context of their work.}

In 1934 theologian Mordecai M. Kaplan coined the phrase 'living in two civilizations' to refer to the potential for people with hyphenated identities to live in a manner that does not compromise either side (Kaplan 1994). Alireza Mashayekhi refers to this reconciliation as Meta-X. In this model, the composer seeks to discover relationships between elements that may be generally viewed as unrelated if not in conflict, where 'different sources and different composition techniques meet one another ... What I'm looking for is quite different from a collage' (Gluck 2007b); rather, he was seeking a greater unity. Mashayekhi's intent is 
also to challenge the insularity with which western and eastern aesthetics developed, suggesting that the composer can play a unique role in allowing each to learn from the other. Mashayekhi's ability to function fully within Iranian and western musical is an instructive example of Hood's concept of bi-musicality, discussed above.

An example is Meta- $X$ No. 1 (c) (2001) for cello, tape and orchestra with Persian instruments (Mashayekhi 2007) (Sound example 5). In this work, Persian and western instruments remain true to their respective traditional intonation and performance techniques (with the addition of extended cello technique). The two elements loosely overlap with related, but not unison, melodic gestures, generally in Persian dastgah (modes) without the use of western harmony. The glue that connects the two is a series of periodic, ambiguous electronic sounds that may be heard in one of two ways: as sound masses of abstracted high pitched cello glissandi or as electronically generated noise. This role of ambiguous agent is sometimes played in Meta-X works without electronics by strummed Persian string instruments and rapidly repeated violin notes, or by percussion. The listener perceives these juxtaposed elements as belonging together to form a distinct, but unfamiliar whole.

Crosscultural models such as Mashayekhi's may prove increasingly significant as countries become increasingly multicultural. To some degree, the shift towards multiculturality is a legacy of colonial histories, but it is also a function of human migration, as people seek economic opportunity, escape from persecution, or reunion with relatives. As a consequence, more people have hyphenated identities, opening broader modalities for ethnic and national identity. Cultural hyphenation expands the range of options available to any individual or subgroup within a subculture, sometimes in unexpected ways. Consider how western music has, for some people, become a lens through which Asian-American identity is parsed and defined (Griffiths 2006; Wang 2006; Yoshihara 2006). Certainly, the impact of multicultural identity on the arts will be an issue to be considered and reconsidered for many years to come.

\section{TOWARDS A REFLECTIVE COMPOSITIONAL PRACTICE}

Two stages of reflection remain. In each of these final stages, the composer is asked to step back from the work completed and reconsider the results of the reflective compositional process. In stage four, the composer seeks to look at the work through the eyes of two theoretical observers. The first assumes the perspective of members of the culture with which one has engaged. The composer calls to mind how select members of the culture in question have responded to the work and (s)he empathetically reviews, once again, how the work might be received within that society. The composer might consider the question 'what if this was another composer addressing aspects of $m y$ own culture?'. Next, the composer assumes the perspective of a dispassionate observer external to the composer's own culture and again considers what conclusions might be drawn about the nature of the work. In short, what might one's peers say? Are there aspects of the work that make me, and maybe others, uncomfortable and, if so, are they of sufficient substance as to suggest a return to an earlier stage in this reflective process? I am not suggesting that music should be comfortable!

Finally, the composer is asked to review the entire experience of the reflective compositional process. Call to mind the various issues addressed in each stage. What initially motivated the decision to engage with aspects of another culture? Why was this particular expression of crosscultural engagement undertaken? What motivated the particular chosen strategy of engagement? Having revised the work during previous stages of the compositional process, how well have areas of concern been addressed? What has been the impact of this process upon the act of composition? What have I learned about myself as a composer and a human being? And, of course, how successful is the work from a musical perspective?

\section{CONCLUSIONS}

This essay has considered music by composers who work within their own cultural traditions or cross into the traditions of other cultures. Some combine multiple traditions within a single work. To enter into another culture raises complex issues and it is not a simple matter to do so while retaining one's own compositional voice. It is my contention that the practitioner should not do so lightly. It is important to identify one's perspective, question one's motives and articulate compelling reasons for entering into domains that others cherish as their inheritance. One can learn by considering the musical implications of historical and cultural context and the sensitivities of members of cultures that have experienced colonialism. New friendships can emerge by asking members of another culture to listen to new works in progress and to learn from their reactions, insights, criticisms, and maybe even appreciations.

Developing sensitivity to the values held within other cultures is not easy because we all tend to see the world through our own lens, experience and values. Those in the West have been raised in societies that share the assumption that western culture reflects universal human norms. Crossing cultural boundaries thus demands a constant internal dialogue, for which I have outlined a five-stage process involving listening, questioning, testing, reconsideration and, through all stages, reflection. One's creative imagination can be voiced without dogmatically asserting it in a non-reflective way 
that treats culturally sensitive resources as materials for harvesting and non-reflective re-interpretation.

Challenges exist even for those who seek to join music from their own distinct cultural backgrounds with contemporary trends. Here, too, reflection is merited. Jin Hi Kim (Kim 2005) speaks about the delicate balance between the integrity of an ancestral musical tradition, the ancient Korean komungo, and its expansion with contemporary technology. The old may be renewed by contact with the new, but as a consequence it will not remain unchanged. In the wrong hands, it can be damaged:

[With proper knowledge] the atmosphere of a traditional instrument and ideas can be extended. The sonic quality is often dramatically changed with electronic technology. This change shouldn't be considered negatively. It is the sound of a new instrument. Therefore, the old musical ideas also need to be changed accordingly. For instance, there is more silence than notes in traditional komungo music, but the electric komungo extends the length of note in space [resulting in less silence]. It is up to a composer/ performer's mindset to [either] create a meeting place between the two or destroying the tradition. If the composer/performer doesn't know much of her own tradition, she cannot do this job.

A reflective compositional process above all implies openness and honesty with ourselves and others, and a willingness to accept criticism and consider changing direction. It means a willingness to seriously converse about issues such as cultural appropriation, but also to acknowledge that these are places where conversation can begin but not necessarily end. Finally, we owe our ancestors, those who cultivated all the forms of cultural expression that we have been so fortunate to inherit, our acknowledgement and gratitude.

\section{REFERENCES}

Adams, John Luther. 2001. Listen globally, make music locally. New Music Box, The Web Magazine from the American Music Center, June. http://www.newmusicbox. org/article.nmbx?id=4142 (accessed 21 July 2007).

Bahn, Curtis. 2007. Personal communication, 18 November.

Baraka, Amiri (LeRoi Jones). 1963. Blues People: The Negro Experience in White America and the Music that Developed from it. New York: William Morrow.

Baraka, Amiri. 1991. The 'Blues Aesthetic' and the 'Black Aesthetic': aesthetics as the continuing political history of a culture. Black Music Research Journal 11(2): 101-9.

Benjamin, Walter. 1969. The work of art in the age of mechanical reproduction. In Illuminations: Essays and Reflections. New York: Schocken. First published in 1935.

Bruyn, Severyn. 1966. The Human Perspective in Sociology: The Methodology of Participant Observation. Englewood Cliffs, NJ: Prentice-Hall.

Burt, Warren. 2007. Personal communication, 12 August.

Cage, John. 1961. The future of music: Credo. In Silence. Middletown, CT: Wesleyan University Press.
Cipriani, Alessandro. 2001. Al Nur, CD CNI 13172 and liner notes.

Coombe, Rosemary. 1997. The properties of culture and the possession of identity: postcolonial struggle and the legal imagination. In Bruce Ziff and P. V. Rao (eds.) Borrowed Power: Essays on Cultural Appropriation. New Brunswick, NJ: Rutgers University Press.

Corbett, John. 2000. Experimental Oriental. In Georgina Born, and David Hesmondhalgh, Western Music and Its Others: Difference, Representation, and Appropriation in Music. Berkeley: University of California Press.

Dal Farra, Ricardo.. 2003. Latin American electroacoustic music collection, Daniel Langlois Foundation. Includes streaming audio files of Alberto Villalpando, Bolivianos! (1973), Ricardo Teruel, Nuestra Cultura Vegeta (1976) and Joaquin Orellana Humanofonia (1971). Web portal: http:// www.fondation-langlois.org/html/e/page.php?NumPage= 542; listening examples: http://www.fondation-langlois. org/html/e/page.php?NumPage $=556$ (accessed 9 September 2007).

Davis, Francis. 1995. The History of the Blues: The Roots, the Music, the People. New York: Da Capo Press.

De Souza, Rodolfo Coelho. 2005. The use of Brazilian folk instrument sounds in a concerto for computer and orchestra. Organised Sound 10(1): 31-6.

Dobrian, Christopher. 2003. Program note for Mannam. http://music.arts.uci.edu/dobrian/Mannam.htm (accessed 17 July 2007).

Dobrian, Christopher. 2004. Strategies for continuous pitch and amplitude tracking in realtime interactive improvisation software. Lecture-demonstration delivered at the 2004 Sound and Music Computing conference, Institut de Recherche et Coördination Acoustique-Musique (IRCAM), Paris, France, October 2004. Published in SMC'04 Conference Proceedings, IRCAM-Centre Pompidou, Paris, France, 201-6.

Dobrian, Christopher. 2007. Cultural 'content' in Korean music made with computers. Lecture delivered in the Korean Studies Forum lecture series at Yonsei University, Seoul, Korea, October 2003. Published in Korean Studies Forum 2: 167-84.

Dolat-shahi, Dariush.. 1985. Sama (1985). On Electronic Music, Tar and Sehtar, Folkways Records CD FTS 37464.

Fischman, Rajmil.. 1999. Global village - local universe. Leonardo Music Journal 9: 53-62.

Fischman, Rajmil.. 2001. Alma Latina. (1997). On Alma Latina, Lorelt-Lontano Records, Ltd., LNT CD 113.

Friedlander, Paul, and Miller, Peter.. 2006. Rock And Roll: A Social History. Boulder, CO: Westview Press.

Gabriel, Peter. 2002. Passion (1989), Geffen Records CD 9 24206-2.

Gluck, Robert. 2003. Sshofar (2002), Shofar (2002) and Shofaralong (2001), on Electric Songs, EMF CD 051.

Gluck, Robert. 2005a. eSaz: a non-western instrument in the context of a live electronic performance system. Organised Sound 10(1): 2005.

Gluck, Robert. 2005b. Cultural identity and interactive art: 'sounds of a community'. Leonardo Music Journal 15: 37-43.

Gluck, Robert. 2005c. Free sound within culturally specific practice. Proceedings of the International Computer Music Conference. Barcelona, September 2005. 
Gluck, Robert. 2006a. Electro-acoustic music in a broader international context. Musicworks 94 (Winter): 61-2.

Gluck, Robert. 2006b. Traditional cultural resources in electro-acoustic music. Living Music Journal 21(2) (Fall 2006-Spring 2007): 14-18.

Gluck, Robert. 2006c. Shahrokh Yadegari (review of Migration). Musicworks 96(Fall): 62-3.

Gluck, Robert. 2006d. Conversation with Halim El-Dabh. EMF Institute, http://www.emfinstitute.emf.org/articles/ gluck.eldabh.html (accessed 9 September 2007). Another version is slated for publication in Journal SEAMUS in 2008.

Gluck, Robert. 2007a. eShofar as a culturally specific live electronic performance system. Journal SEAMUS 19(Fall): $10-16$.

Gluck, Robert. 2007b. Interview with Alireza Mashayekhi. 28 July and 13 December 2006; 7 January 2007 by email. http://www.emfinstitute.emf.org/articles/gluck.mashayekhi_ 07.html.

Griffiths, Daniel. 2006. Classical music takes Chinese stage, BBC News, Beijing, web news website. http://news. bbc.co.uk/2/hi/asia-pacific/4200906.stm (accessed 13 July 2007).

Hall, Edward T. 1959. The Silent Language. New York: Doubleday.

Hall, Edward T. 1966. The Hidden Dimension. New York: Doubleday.

Hall, Edward T. 1976. Beyond Culture. New York: Doubleday.

Harvey, Jonathan. 1999. Music and Inspiration. London: Faber and Faber.

Hood, Mantle. 1960. Bi-musicality. Ethnomusicology 4: 55-9. hooks, bell. 1990. Yearning: Race, Gender and Cultural Politics. Toronto: Between the Lines Press.

Hungarian Academy of Sciences Institute for Musicology. 2005. Bartók Archive on the web: http://www.zti.hu/bartok/ exhibition/en_P6.htm (accessed 3 September 2007). Quotation from a deleted passage of Bartók's 'Budapest' lecture of 1931, published in Tibor Tallián, Béla Bartók. The Man and His Work (Budapest, 1988), 133.

Hwang, Sung Ho. 1999. Contrast (1993) for daegum and electronic. On $T V$ Scherzo, Korean National University of Arts, School of Music Faculty Works Vol. 5 CD.

Kaplan, Mordecai. 1994. Judaism as a Civilization: Toward a Reconstruction of American Jewish Life. New York: Jewish Publication Society. First published in 1934.

Kapur, Ajay. 2007a. California Institute of the Arts website: http://www.calarts.edu/faculty_bios/music/faculty/ajaykapur/ ajaykapur (accessed 18 November 2007).

Kapur, Ajay. 2007b. Program notes to 'Digital Sankirna' on 'Far and Wide' CMJ 2007 DVD. Computer Music Journal 31(4) (Winter).

Kim, Jin Hi. 2001a. Komungo. La Folia 3(4) (August) http:// www.lafolia.com/archive/kim/kim200108komungo.html (accessed 17 July 2007).

Kim, Jin Hi. 2001b. Komungo, oodiscs CD oo70.

Kim, Jin Hi. 2005. Personal communication by email, 20-21 January 2005.

Keyes, Christopher J. 2005. Recent technology and the hybridization of Western and Chinese musics. Organised Sound 10(1): 51-6.
Lewis, George E. 1996. Improvised music after 1950: Afrological and Eurological perspectives. Black Music Research Journal 16(1): 91-122.

Mahon, Maureen. 2004. Right to Rock: The Black Rock Coalition and the Cultural Politics of Race. Durham, NC: Duke University Press.

Mashayekhi, Alireza. 1988. Concerto for Violin and Orchestra, op. 96. On Tehran Symphony, Mahoor Institute of Culture and Art CD 145.

Mashayekhi, Alireza. 2002. Chahargah II, for tar, violin, orchestra and tape, op. 140 (1999). On Iranian Orchestra for New Music, Hermes Records CD HER-009.

Mashayekhi, Alireza. 2004. A la recherche du temps perdu, op. 111 (1994) and Short Stories, op. 106 (1993). On Music for Piano. Hermes Records CD HER-020.

Mashayekhi, Alireza. 2005. Shur (1968) and East-West (1973). On Happy Electronic Songs, Music Center of Hoze-ye Honari CD (3-CD set).

Mashayekhi, Alireza. 2007. Meta-X No. 1 (c), for cello, tape and orchestra with Persian instruments (2001), private recording in the collection of the composer.

Metropolitan Museum of Art (NYC) website: www. metmuseum.org/Works_of_Art/viewOne.asp?dep $=6 \&$ viewMode $=0 \&$ item $=$ JP1847 $($ accessed 26 June 2007).

Nagata, Adair Linn. 2004. Promoting self-reflexivity in intercultural education. Journal of Intercultural Communication 8: 139-67.

Phinney, Kevin. 2005. Souled American: How Black Music Transformed White Culture. New York: Billboard Books.

Rabinowitz, Peter J. 1991. Whiting the wrongs of history: the resurrection of Scott Joplin. Black Music Research Journal 11(2): 157-76.

Rogin, Michael. 1998. Blackface, White Noise: Jewish Immigrants in the Hollywood Meltingpot. Berkeley: University of California Press.

Said, Edward. 1978. Orientalism. New York: Pantheon Books.

Said, Edward. 1993. Culture and Imperialism. New York: Alfred A. Knopf, Inc.

Schaeffer, Pierre. 1966. Traité des objets musicaux. Paris: Editions du Seuil.

Schafer, R. Murray. 1977. The Tuning of the World. New York: Random House Inc.

Schon, Donald. 1983. The Reflective Practitioner: How Professionals Think in Action. London: Temple Smith.

Simon, Paul. 1997. Graceland (1986), Rhino Records CD 78904.

Simon, Paul. 2004. The Rhythm of the Saints (1990), Rhino Records CD 78905.

Spradley, James. 1980. Participant Observation. New York: Harcourt Brace.

Sprague, R. H. 1980. A framework for the development of decision support systems. MIS Quarterly 4(4): 1-26.

Stockhausen, Karlheinz. 1966. Liner notes from the original recording of Telemusik, Deutsche Grammophon Gesellschaft LP 137012.

Stockhausen, Karlheinz. 1978. Weltmusik (1973). Texte zur Musik, Vol. 4, Cologne: Verlag M. DuMont Schauberg, 1970-77, pp. 468-76. Available on the web: http:// www.stockhausen.org/stockhausen_texts.html (accessed 3 October 2007). 
Takemitsu, Toru. 1994. November Steps (1967), on Visions, Denon CD CO-79441. Also on Takemitsu 1991, Viola Concerto, Philips CD 432 176-2.

Takemitsu, Toru. 1995. Confronting Silence: Selected Writings. Berkeley, CA: Fallen Leaf Press.

Teitelbaum, Richard. 1972. World Band. Soundings, 1.

Teitelbaum, Richard. 2007. Personal communication, 10 July 2007.

Wade, Bonnie C. 2005. Music in Japan. New York: Oxford University Press.

Whalley, Ian. 2005. Traditional New Zealand Maori instruments, composition and digital technology: some recent collaborations and processes. Organised Sound 10(1): 57-65.

Wang, Grace. 2006. Constructing an Asian American practice through western classical music. Unpublished manuscript, presented at the American Studies Association. Abstract is available at http://www.allacademic.com/meta/p114158_ index.html (accessed 13 July 2007).

Weisgall, Hugo. 1959. The music of Henry Cowell. Musical Quarterly 45: 498.
Westerkamp, Hildegard. 2002. Liner notes from Into India. Earsay CD ES 02002.

White, Frances. 1990. Composer and material in musique concrète. http://www.rosewhitemusic.com/concrete.html (accessed 10 September 2007).

Wilson, Olly. 1983. Black music as an art form. Black Music Research Journal 3: 1-22.

Yadegari, Shahrokh. 2004. The radif as a basis for a computer music model: union of philosophy and poetry through selfreferentiality. Unpublished $\mathrm{PhD}$ thesis, University of California, San Diego. http://crca.ucsd.edu/ syadegar (accessed 14 July 2007).

Yao, Dajuin. 1999. cinnabar red drizzle. Post Concrete: Berkeley, CD: POST 001.

Yoshihara, Mari. 2006. From the freighter to the podium: Japanese and Japanese Americans in western classical music. Unpublished manuscript, presented at the American Studies Association. Abstract is available at http://www.allacademic.com/meta/p95719_index.html (accessed 13 July 2007). 